\title{
Etnografía, Arqueología y recursividad en la comunidad alfarera de Chipihuayco (Modesto Omiste, Bolivia)
}

Ethnographie, archéologie et $r$

dans la communauté

de potiers de

Chipihuayco (Modesto Omiste, Bolivia)

Ethnography, Archaeology and Recursiveness in the pottery community of

Chipihuayco (Modesto Omiste, Bolivia)

Florencia Ávila

\section{(2) OpenEdition}

\section{Journals}

Edición electrónica

URL: https://journals.openedition.org/bifea/11873

DOI: 10.4000/bifea.11873

ISSN: 2076-5827

Editor

Institut Français d'Études Andines

Edición impresa

Fecha de publicación: 1 abril 2020

Paginación: 153-170

ISSN: 0303-7495

Referencia electrónica

Florencia Ávila, «Etnografía, Arqueología y recursividad en la comunidad alfarera de Chipihuayco (Modesto Omiste, Bolivia)», Bulletin de l'Institut français d'études andines [En línea], 49 (1) | 2020, Publicado el 08 agosto 2020, consultado el 25 agosto 2021. URL: http://journals.openedition.org/ bifea/11873 ; DOl: https://doi.org/10.4000/bifea.11873

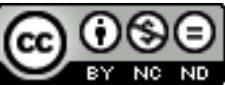

Les contenus du Bulletin de l'Institut français d'études andines sont mis à disposition selon les termes 
de la licence Creative Commons Attribution - Pas d'Utilisation Commerciale - Pas de Modification 4.0 International. 


\title{
Etnografía, Arqueología y recursividad en la comunidad alfarera de Chipihuayco (Modesto Omiste, Bolivia)
}

\author{
Florencia Ávila*
}

\section{Resumen}

En este trabajo me propongo desarrollar una discusión general, desde un enfoque recursivo, acerca de ideas y conceptos que considero importantes para ayudar a pensar cuestiones sobre el universo de la producción cerámica, entendiéndola como una «práctica nuclear» de las comunidades andinas con las que trabajo. Desde una etnografía arqueológica discuto la noción de comunidad en tanto «ensamble» de agencias humanas y no humanas y de redes afectivas en tanto vías de «compromiso» social. Utilizo el caso de la comunidad alfarera de Chipihuayco, ubicada en los valles del sur de Bolivia, para ejemplificar los conceptos esgrimidos.

Palabras clave: etnografía arqueológica, recursividad, práctica nuclear, comunidad alfarera, sur de Bolivia

\section{Ethnographie, archéologie et récursivité dans la communauté de potiers de Chipihuayco (Modesto Omiste, Bolivia)}

\section{Résumé}

Dans cet article, j'entends développer une discussion générale à partir d'une approche récursive, autour d'idées et de concepts que j'estime importants pour aider à réfléchir sur les questions relatives à l'univers de la production de la céramique, vue comme une «pratique nucléaire» des communautés andines avec lesquelles je travaille. À partir d'une ethnographie archéologique, je discute de la notion de communauté en tant qu'«ensemble» d'agences humaines et non humaines, et des réseaux affectifs comme moyen d'«engagement» social. Pour illustrer mon analyse, j'ai recours au cas de la communauté de potiers de Chipihuayco, située dans les vallées du sud de la Bolivie.

* Investigadora Asistente del Consejo Nacional de Investigaciones Científicas y Tecnológicas (CONICET). Instituto Nacional de Antropología y Pensamiento Latinoamericano (INAPL). E-mail: florenciaavila@gmail.com 
Mots-clés : ethnographie archéologique, récursivité, pratique nucléaire, communauté de potiers, sud de la Bolivia

\title{
Ethnography, Archaeology and Recursiveness in the pottery community of Chipihuayco (Modesto Omiste, Bolivia)
}

\begin{abstract}
In this paper I present a general discussion, using a "recursive" approach, of ideas and concepts that I consider important to improve the study of ceramic production by Andean communities. I understand this as a "nuclear practice". Based on archaeological ethnography, I discuss the notion of community as an "assembly" of human and non-human agencies, and "affective networks" as a means of social "commitment". To exemplify my approach to analysis, I present the case of the pottery community of Chipihayco, located in the valleys of southern Bolivia.
\end{abstract}

Key words: Archaeological ethnography, recursion, nuclear practice, pottery community, southern Bolivia

\section{INTRODUCCIÓN}

Desde hace varios años mi trabajo arqueológico y mi esquema epistemológico se han visto continuamente desafiados y «afectados» (Favret Saada, 1990) por el contacto con comunidades campesinas del sur de Bolivia con las cuales trabajo. Este contacto e interés me llevaron a desarrollar, desde una etnografía arqueológica (González Ruibal, 2017), un estudio sobre el universo de la producción cerámica de estos grupos. Durante el mismo, en diversos momentos, tuve que enfrentarme a situaciones donde las explicaciones de la propia comunidad se contrastaban con las mías. Esta situación me llevó a preguntarme: ¿cómo poder entender la diferencia entre mi mundo y el de ellos? Y en relación a esto, ¿cómo escapar de la obvia violencia epistémica ${ }^{1}$ del discurso arqueológico y etnográfico en sociedades poscoloniales? ¿Cómo pensar en una etnografía arqueológica a partir del otro?

Coincido con algunas propuestas que sugieren que una posibilidad de democratizar el relato del pasado y del presente es habilitar enfoques que traten con paridad teorías antropológicas, filosofías occidentales y prácticas y pensamientos de pueblos indígenas (Alberti \& Marshall, 2009; Haber, 2013). Que exista la posibilidad de «plurirrelatos» en los que se permita que las «alteridades» narren sus propias historias (Minh-ha, 1989; Spivak, 2011). Partiendo de estas ideas, más que construir modelos de investigación rígida, tomé como objetivo generar ámbitos de experimentación mental, desde los cuales sobreponerme

1 Me refiero a violencia epistémica (Spivak, 2011) o a predación ontológica (Viveiros de Castro, 2013), cuando una subjetividad más poderosa domina y objetiva una más débil. 
a las contradicciones 2 que estancaban las descripciones iniciales de mi trabajo (Holbraad, 2009), formulando así bases de datos y percepciones etnográficas abiertas a desafíos ontológicos 3 alternativos (Allen, 2017). De todas formas, continúo preguntándome, ¿cómo trabajar con modalidades ontológicas diferentes? ¿Cómo abordar la diversidad de sentidos que encierran las prácticas y los objetos? ¿Cómo dar lugar a formas diferentes de organizar y narrar historias?

Viveiros de Castro (2013: 477) nos Ilama a «tomar en serio» otras explicaciones válidas, otras formas de conocimiento de la realidad. Por «tomar en serio» al otro, este autor se refiere a aceptar como verdadera su realidad. Un ejemplo clásico que utiliza es la afirmación que realiza un grupo indígena amazónico: «los pecaríes son humanos». Normalmente, la tarea antropológica convencional hubiese sido explicar el sentido de esta enunciación «para ellos». Contrastando con esta posición, lo que es de interés, afirma Viveiros de Castro, no es que pensemos que estos animales son personas, sino «żqué están diciendo los amerindios cuando afirman que los pecaríes son humanos?» (Viveiros de Castro, 2013: 494). Así podemos pensar que los abordajes ontológicos tratan de dar lugar y credibilidad a la posibilidad de «otros mundos», no como un gesto relativizante, sino como estrategia de producción de nuevos conceptos y materialidades (Viveiros de Castro 2013). Sin duda estas ideas nos obligan a repensar nuestras posiciones como antropólogos/arqueólogos y la brecha entre mundos de entendimientos, por lo que tratar de reflexionar sobre nuevas maneras de pensar «la realidad» y los «compromisos ontológicos» que esto conlleva se vuelve esencial (Alberti et al., 2011).

Estas ideas sobre el lugar y la importancia de «tomar en serio» la ontología del otro, están asociadas a una línea que diversos arqueólogos vienen desarrollando en los últimos tiempos. Entre ellas se encuentran las Arqueologías Relacionales de Gnecco (2009), las Arqueologías Indisciplinadas de Haber (2013), la Arqueología Recursiva de Alberti (Alberti \& Marshall, 2009; Alberti, en prensa) o, más recientemente, la Arqueología Indígena de Petry Cabral (2014).

A pesar de ser heterogéneos, el punto en común de estos acercamientos es la propuesta de «tomar en serio» las ideas y las prácticas de personas y grupos cualesquiera sean ellas. Es también reflexionar sobre otras formas de entender la materialidad, sus relaciones y la composición de los mundos en nuestros estudios sobre el pasado (y el presente). El arqueólogo Alberti propone un «enfoque recursivo» que trabaja con lo material para maximizar el potencial para que la diferencia ontológica pueda aflorar. Su modelo se preocupa por usar la diferencia ontológica como una herramienta que permita teorizar el material arqueológico y desafiar el significado de conceptos generales en casos particulares. En otras

2 Cuando me refiero a contradicciones, estoy pensando en la complejidad que significa el encuentro con el otro, en las relaciones de poder que la ciencia impone, en la violencia epistémica y el silenciamiento de ontologías diferentes. Todo este equipaje espistémico con el que, en general, somos formados en la academia amplía las distancias con el «otro»y, por lo tanto, precisa ser confrontado y cuestionado.

3 Me hago eco de las palabras de González Ruibal para pensar en la ontología como «la constitución del ser en su dimensión profunda, temporal, espacial y subjetiva» (González Ruibal, com. pers.). 
palabras, busca reconocer y sentir el impacto de la alteridad latente en la materialidad:

Para algunos arqueólogos y antropólogos, recurrir a la ontología es un movimiento corrector destinado a describir una nueva metafísica, una que se adapte mejor a la condición del mundo (por ejemplo, Alberti et al., 2011; Ingold, 2013). Es decir, son nuevas teorías de realidad; nuevas formas de describir lo real basado en un importante esfuerzo filosófico y físico, que tiene como objetivo mejorar nuestros modelos ontológicos (Alberti, en prensa: 6, traducción propia).

Alberti se apoya en los planteos del antropólogo Holbraad (2009) para sostener que en lugar de solo usar nuestros conceptos analíticos para dar sentido a una etnografía arqueológica determinada (explicación, interpretación), demos lugar a la etnografía para pensar nuevos sentidos de nuestros propios conceptos. De esta forma, el mérito del enfoque recursivo consiste en estar diseñado para permitir que nuestras teorías y conceptos sean vulnerables a la transformación en nuestro encuentro con la alteridad.

Para Alberti, entonces, una arqueología que se pregunte por dimensiones

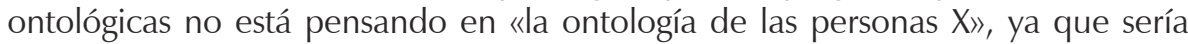
tratarlo como «creencias o teorías sobre la realidad» de grupos específicos. Sería afirmar que hay una única realidad. Por este motivo, Alberti propone un enfoque ontológico ${ }^{4}$ con una metodología flexible, que cree dispositivos analíticos para que afloren las diferencias ontológicas de modo de confrontar nuestros presupuestos y conceptos. Quizás, el mayor desafío de una arqueología recursiva consiste en que la propuesta de Holbraad de una «recursividad antropológica» no fue pensada para contextos en los que el otro está representado solo por los restos materiales de su cultura. Por tanto, ¿cómo extraer la ontología a partir de objetos prehispánicos?5

A partir de las ideas mencionadas, en el marco de un trabajo que es más inicial que conclusivo, me propongo discutir algunas cuestiones y conceptos que considero pueden ser un punto de partida interesante para reflexionar sobre formas alternativas de construcción de conocimiento «desde el otro» y no «sobre

4 "La "ontología" en general suele aparecer de forma poco clara en la literatura. (...) En arqueología, "ontología" es a menudo sinónimo de la realidad misma, "lo que hay" (Fowler, 2013: 61), y también de lo que las personas afirman que es realidad, "un conjunto fundamental de conocimientos sobre cómo el mundo es" (Harris \& Robb, 2012: 668). La diferencia básica entre ambas es esta: uno conceptualiza la ontología como las "creencias sobre" la realidad de un pueblo, el otro como la única realidad de un pueblo, sus compromisos ontológicos reales. Estas posiciones son claramente distintas. El primero es más que nada un tipo de construcción cultural de discursos y argumentos, donde la idea de realidad se mantiene incuestionable, mientras que la segunda implica objetar e investigar el terreno sobre el que nos apoyamos nosotros y nuestras teorías» (Alberti, 2016: 170, traducción propia).

5 Podemos citar dos ejemplos en los que se trabajó, desde un enfoque recursivo, con material precolonial. El primero de ellos fue realizado por el propio Alberti (2013) sobre el corpus alfarero Candelaria del Noroeste Argentino; el segundo, sobre los «paquetes sagrados» mayas de Mesoamérica trabajado por Grecco Pacheco (2019). A ambos me remito para mayor detalles. 
el otro». Así, en primer lugar, voy a analizar la propuesta de una etnografía arqueológica del presente propuesta por González Ruibal (2017) para ver los puntos y contrapuntos con mi propia postura. Posteriormente, pienso discutir el potencial de una «etnografía arqueológica recursiva», a través de un pequeño ejemplo, sobre prácticas cerámicas en los valles alfareros del sur de Bolivia, en particular en la comunidad de Chipihuayco. Es importante dejar claro que estoy lejos de presentar un modelo de análisis cerrado, sino tan solo mostrar el potencial que este tipo de abordajes tiene para convertirlos en herramientas de análisis con capacidad argumentativa.

\section{ETNOGRAFÍA ARQUEOLÓGICA Y OBJETOS NUCLEARES}

En una de sus contribuciones, González Ruibal (2017) discute algunas cuestiones centrales para pensar críticamente los objetivos y las limitaciones de la etnoarqueología, de la etnografía arqueológica y de la Arqueología. Se realiza una división en cuatro perspectivas:

a) La etnoarqueología clásica que, a partir de preguntas y metodologías arqueológicas, busca generar puentes analógicos entre sociedades presentes y pasadas, con el fin de testear teorías de rango medio (Schmidt, 2010) o el paso de contextos sistémicos (vivos) a arqueológicos (Schiffer, 1972). El problema que reviste este enfoque es el desinterés por las sociedades vivas per se, o la negación de la contemporaneidad de las comunidades estudiadas.

b) La etnografía arqueológica como práctica autoreflexiva que critica el distanciamiento generado por la ciencia hacia las sociedades actuales y hacia la propia disciplina, sin comprometerse públicamente (Hamilakis \& Anagnostopoulos, 2009). El peligro sería de caer en una etnografía muy poco arqueológica, con el riesgo de que la autocrítica recaiga en un ensimismamiento disciplinario.

c) La etnoarqueología desde una perspectiva posprocesual, que propone efectuar, como estrategia de análisis, descripciones densas (como la propuesta por el antropólogo Geertz), con el objetivo de «develar» estructuras simbólicas, restaurando el sentido de pensamientos y discursos (Tilley, 1997; Verhoeven, 1999). El problema para González Ruibal es que la etnografía no sería la mejor manera de ofrecer descripciones de los mundos sociales, además que «no encuentro entre la mayoría de etnógrafos/as un interés real en la materialidad» (González Ruibal, 2017: 270).

d) La etnografía arqueológica que tiene en cuenta la materialidad, la multitemporalidad y las experiencias alternativas de la historia y los lugares, a partir de descripciones materialmente densas de sociedades presentes y pasadas. Esta es la perspectiva adoptada por González Ruibal6, una etnografía

6 Si bien comparto gran parte de lo propuesto por González Ruibal, creo que para conocer una comunidad en profundidad y establecer relaciones de confianza y afecto, es necesario que el 
arqueológica que no sea un puente entre el presente y el pasado, sino una herramienta para discutir al otro cultural contemporáneo desde lo material.

De hecho, para González Ruibal, el lugar de la ontología en el trabajo etnográfico es un elemento relevante que sustenta las diferencias en su clasificación de tipos de etnoarqueologías, por lo que, retomando a Viveiros de Castro, plantea «tomar en serio» la materialidad. Esto implica repensar algunas suposiciones que se han dado por hecho en las ciencias sociales, como la centralidad absoluta de la agencia humana. En esta nueva perspectiva, los papeles sociales se distribuyen indistintamente entre actores humanos y no humanos (Hodder, 2012; Olsen et al., 2012). Una aproximación ontológica a los objetos considera que las ecologías de humanos y no humanos están entrelazadas en el mismo plano existencial (Webmoor \& Witmore, 2008). Sin embargo, estas ecologías son profundamente diferentes en distintas sociedades. Precisamente, las aproximaciones ontológicas recientes enfatizan esta diversidad (Alberti \& Marshall, 2009; Alberti et al., 2011; González Ruibal, 2017).

Otro concepto interesante, que retomaré más adelante, es el de «objeto nuclear», utilizado por González Ruibal para dar cuenta de particularidades ontológicas desde la materialidad (Boesch Ernst, 1991: 333 in González Ruibal, 2017). Estos core objects, son aquellos objetos que, por sus usos y conexiones rituales, parecen ser vitales para la autodefinición de una determinada sociedad. Es decir, existen objetos que poseen un papel ontológico central, cuya modificación, transformación o desaparición afectaría la comunidad. Objetos que pueden ir desde estructuras funerarias, vestimenta, armas y hasta pinturas. Este concepto parece tener potencial para ayudarnos a reflexionar sobre la cerámica, en especial asociación con las concepciones de comunidad y redes afectivas.

\section{COMUNIDADES Y REDES AFECTIVAS}

Las ideas que presentaré a continuación son parte de un proceso de aproximación y reflexión etnográfica para pensar cuestiones sobre el universo andino de producción cerámica. Este proceso viene siendo desarrollado con la comunidad alfarera de Chipihuayco desde hace más de siete años, y se encuentra enmarcado dentro de un proyecto más amplio de investigación arqueológica, histórica y etnográfica de la producción alfarera en el valle de Talina7. Para seguir con la línea argumentativa, voy a discutir, en primer lugar, los conceptos de comunidad y red de afectos, para posteriormente traer un ejemplo acotado y simple relacionado con un ritual propiciatorio para la producción alfarera.

investigador destine un tiempo cualitativo a la misma. Solo así será posible explorar nuevas formas de entendimiento y construcción interepistémica. A mi parecer, es difícil ser «afectados» o entender al otro «en sus propios términos» si no es a partir de este camino.

7 Este proyecto está financiado por el Consejo Nacional de Investigaciones Científicas y Técnicas (CONICET, Argentina). Para el mismo se realizaron tareas de campo intensivas (entre 60 a 70 días al año) entre 2012 y 2018. A nivel metodológico, se trabajó principalmente a partir de las notas de campo, producto de conversaciones con diversos interlocutores. Estas charlas se formularon 
Los estudios teóricos sobre la formación de comunidades sociales han tenido como común denominador, siguiendo la línea de Bourdieu y Giddens, la práctica, la agencia y la estructura social; poniendo así en relevancia el compromiso de las personas con un mundo histórico y dinámicamente construido (Varien \& Potter, eds., 2008; Canuto \& Yaeger, 2000). La comunidad no es algo preconcebido, sino algo que emerge de un interjuego entre personas y prácticas. Si bien es importante el espacio que ocupa, dado que se requiere una cercanía entre los sujetos, no es requisito primordial. Es por ello que no pienso en corresidencia, sino en copresencia. La comunidad es interacción cara a cara, pero también es dinámica, transformadora y emergente en la práctica. La comunidad se construye a través de compromisos emocionales con las cosas, siendo estas cualidades sensibles las que crean las relaciones en la práctica. Por todo esto, una comunidad no es lo que las personas tienen, es lo que las personas hacen.

Cuando me refiero a compromisos, pienso en acuerdos de responsabilidad mutua entre actores. Y es, en esta relación, en donde las comunidades se crean y se reproducen: en relación. Así es como los actores se comprometen nuevamente formando redes afectivas y emotivas, «los campos afectivos son el resultado de ensambles particulares» (Harris \& SØrensen, 2010: 150). Es por eso que pienso en la comunidad como ensambles dinámicos, donde se interrelacionan lugares, memorias, agencias humanas y no humanas, alteridades e identidades, unidos bajo compromisos afectivos, en prácticas situadas, copresenciales y reales (Harris, 2014; Harris \& SØrensen, 2010; Webmoor \& Witmore, 2008).

\section{LA COMUNIDAD DE CHIPIHUAYCO}

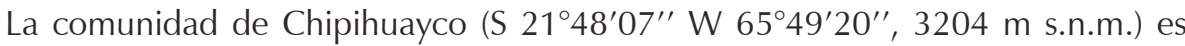
cabeza de cantón del municipio Villazón, en el noroeste de la provincia Modesto Omiste, sur del departamento de Potosí, Bolivia (fig. 1). La comunidad tiene 200 habitantes (según el Censo Nacional de Población y Vivienda de 2012), nucleados en 30 familias que hablan fluidamente, al igual que los pueblos circundantes, el quechua y el castellano. Al ser una quebrada angosta, producto de la erosión fluvial del Talina, la cantidad de espacio productivo se ve restringido y es usado intensivamente. Por esta razón, el patrón de asentamiento de la comunidad se configura como una suerte de salpicado de viviendas (entre 3 o 4 juntas) circundado por chacras, en una distancia total de $8 \mathrm{~km} \mathrm{~N}-\mathrm{S}$ y 2,5 km E-O. A su vez, en su margen derecha, se encuentra el sitio arqueológico Maukallacta de Chipihuayco que, por su gran tamaño (más de 60 ha), ocupa casi la mitad del poblado actual. Las investigaciones realizadas muestran que se trataba de un asentamiento de

de modo de ser replicables, a partir de temas de interés entre cada una de las partes (ellos y yo) y se transformaron en un puente de conexión intraontológico. Por su parte la cámara fotográfica y la grabación audiovisual actuaron como plataformas para registrar actuaciones rituales (en las ocasiones en las que fueron autorizadas) así como elementos de la cotidianeidad que se consideraron importantes. 


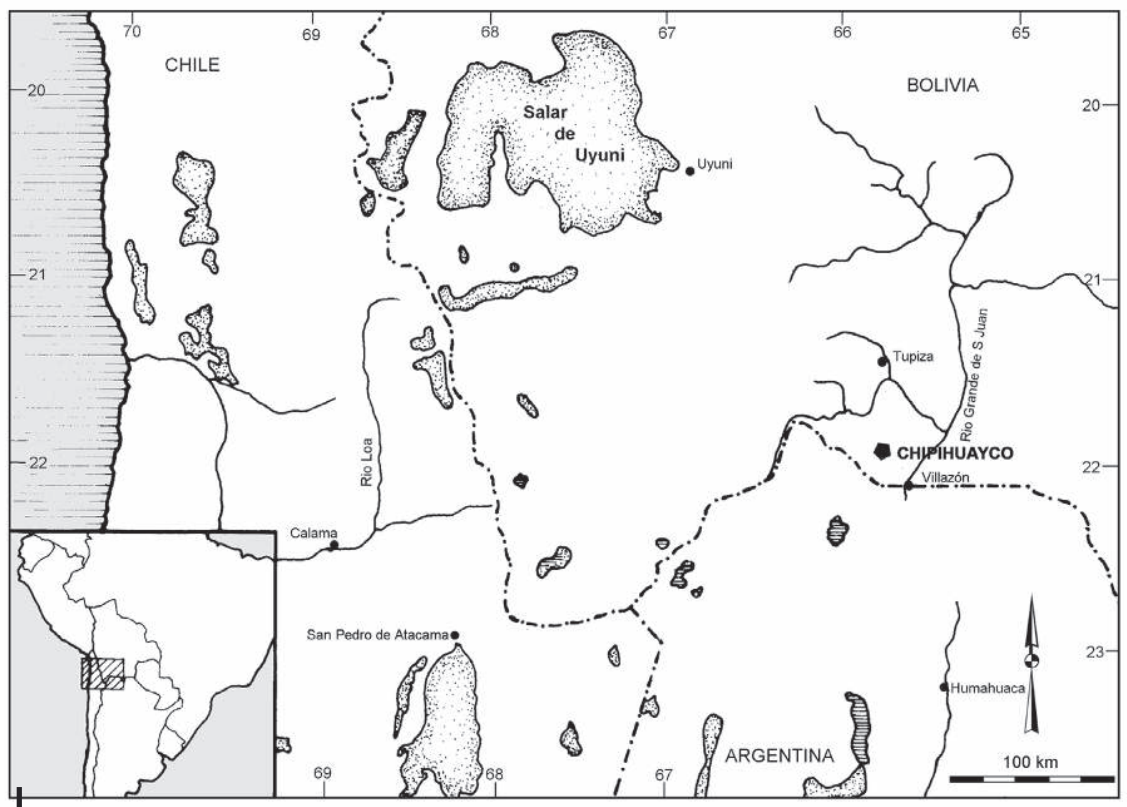

Figura 1 - Ubicación de la comunidad de Chipihuayco en el área circumpuneña

(C) Florencia Ávila

gran complejidad estructural, con espacios públicos o plazas jerarquizadas, redes de calles, sectores de edificación de distinto trazado y contornos bien definidos. Cronológicamente se situaría entre los siglos XIII y XV, cuando fue parcialmente quemado, tal vez como consecuencia de la ocupación incaica en el valle (Ávila, 2013).

Los límites políticoadministrativos de la región también operan como una suerte de división entre pueblos alfareros y no alfareros. De Chipihuayco al sur existen doce comunidades de artesanos ceramistas: Chipihuayco, Chaquicocha, Esquiloma, Villa Rosario, Quesera, Churquipampa, Tica Cancha, Chagua, Berque, Casira Grande, Casira Chica, Calahoyo. Todas ellas presentan características rurales, con producción agrícola de cultivos microtérmicos (tubérculos y quínoa) y mesotérmicos (maíz), cría de ganado (caprino, camélido), complementada por la elaboración de piezas de alfarería. Es la región con mayor producción alfarera del centro-sur de Bolivia. De hecho, tienen una suerte de marca personal de calidad; «es olla de Talina» comentan en el mercado campesino de Villazón para referirse a una pieza proveniente de cualquiera de estas comunidades. Podemos encontrarlas en ferias campesinas y también son compradas al por mayor por intermediarios para los mercados de Potosí y Tarija, en Bolivia, así como Jujuy, Salta y Buenos Aires, en Argentina.

En el valle, utilizando materia prima local, se confeccionan ollas, cántaros, tinajas, virques $^{8}$ y vajilla de servicio (cuencos, fuentes, vasos, jarras). Se usa la técnica del

8 Vasijas de boca ancha utilizadas para hacer chicha (bebida alcohólica a base de maíz). 
rollo, paleteado y/o mixta, y se utilizan herramientas de madera para el levantado y de piedra para el alisado (fig. 2). La cocción se realiza en fogones a cielo abierto o semiabierto empleando como combustible bosta de buey, de chivo, de llama y vasijas rotas a modo de material refractario (fig. 3) ${ }^{9}$. En Chipihuayco, bajo una economía de base agrícola, la alfarería es un «complemento» de la entrada de capital per cápita fuera de la temporada de lluvias (abril a noviembre).

Más del $80 \%$ de la población femenina adulta de la comunidad tiene este oficio. Pero ¿cómo se convierte una persona en alfarera? El aprendizaje es muy variado, puede estar mediado por relaciones de parentesco (madre, abuela, tía, madrina),
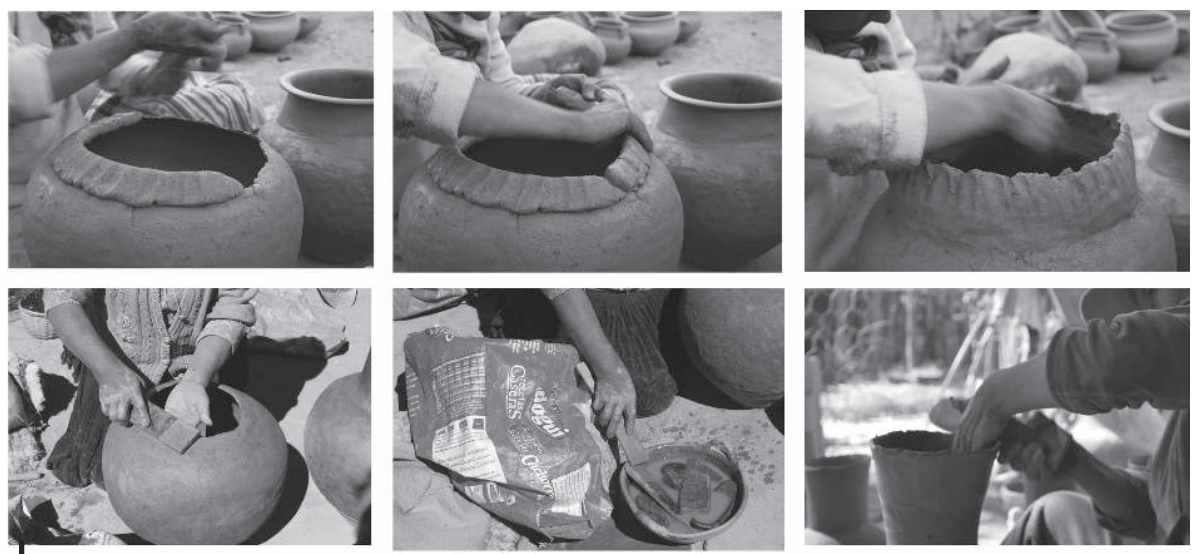

Figura 2 - Proceso de levantado de las piezas

(c) Florencia Ávila
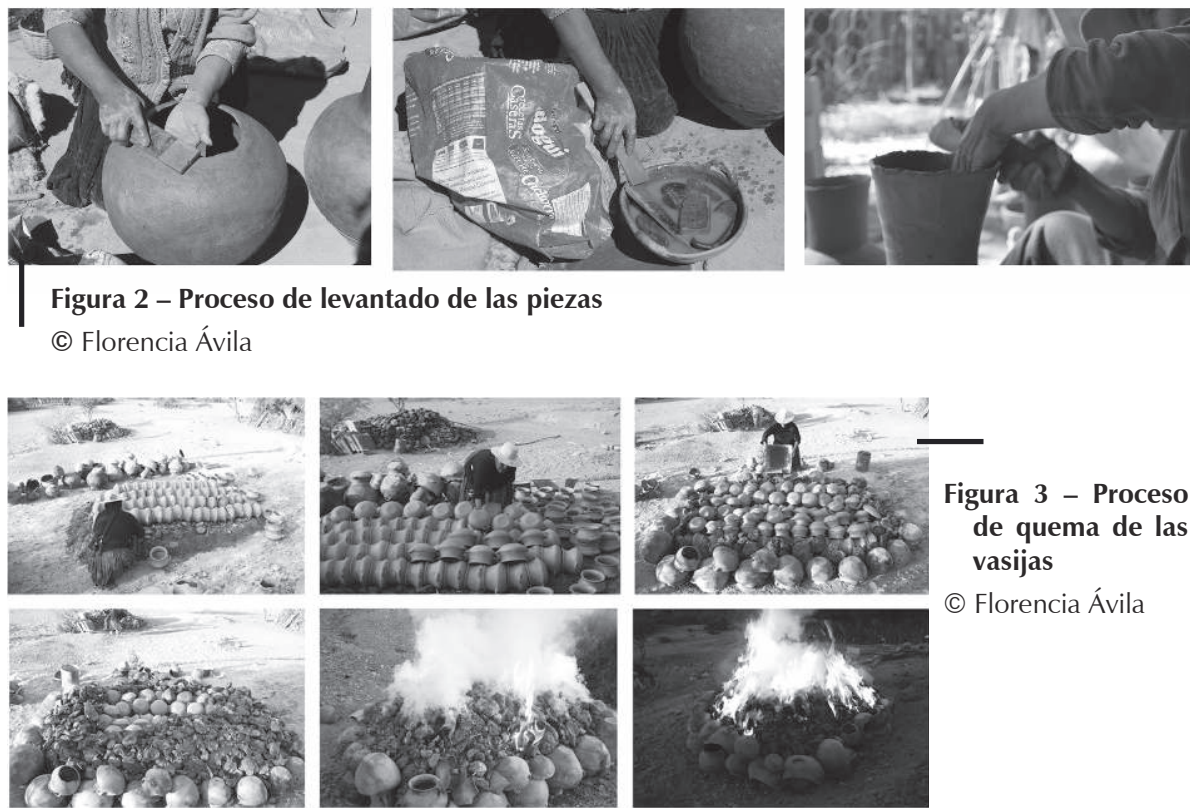

Figura 3 - Proceso de quema de las vasijas

(c) Florencia Ávila
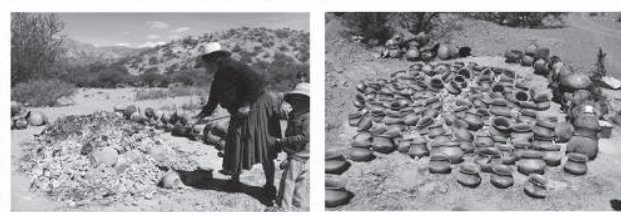

9 Más datos sobre la producción alfarera de la Quebrada se encuentra en el informe técnico realizado por la secretaría de cultura de la Alcaldía de Tupiza (Gutiérrez, 2005) y en los volúmenes publicados por Sapiencia de Zapata et al. (1997) y Ramírez Rivas (2014). 
de parentesco político (en algunos casos se ha aprendido de la suegra) o por vecindad (se aprendió de una vecina). Lo cierto es que una puede denominarse alfarera cuando constituye su propia unidad doméstica. Una vez que se contrae matrimonio y se construye la vivienda familiar, la alfarera se apropia de su título llevando a cabo ciertas acciones. Por un lado, establece en su casa cual será el lugar del taller, de descanso del barro y del sector de la quema. Por otro, se elige el kit de instrumentos y las materias primas que la acompañarán. Se crea asî una relación intersubjetiva con todos estos elementos que evocan otros seres: la alfarera (Manka Llujta), el barro (Pacha-tierra) y el antiplástico (Apu-Cerro).

Anteriormente propuse pensar a las comunidades como ensambles. En este marco, el ritual ofrecido al cerro pone de relieve esta relación intersubjetiva, haciéndola situada, en presencia, y amalgamada por un espíritu afectivo. La fuerza de los rituales deriva de su poder para reproducir y transformar identidades, contextos de acción y significados comunitarios. Es por ello que considero que analizar un ritual, en este caso asociado a las alfareras, desde lo que llamé una «etnografía arqueológica recursiva», funciona como una especie de prisma multiconceptual que permite un acceso a experiencias metaontológicas. En otras palabras, la posibilidad de iniciar relaciones con el otro a partir de sus propios conceptos y prácticas nos permite acceder a universos relacionales ${ }^{10}$ en donde coexisten agencias humanas y no humanas.

\section{RITUALES PROPICIATORIOS Y ACUERDOS SOCIALES}

Mi relación con la comunidad comenzó años antes que la actual investigación en curso. Me instalé ahí para estudiar el sitio arqueológico. Realicé en aquel lugar no solo el trabajo de campo, sino también el de laboratorio (por disposición ministerial todo material arqueológico queda al resguardo de la comunidad a la que jurisdiccionalmente pertenece). Dado que estoy especializada en alfarería prehispánica, analicé cada tiesto y remonté cada vasija a la vista de todos, lo que suscitó las más diversas reacciones entre los comuneros. Cuando decidí comenzar mi actual investigación, expresé mi deseo de aprender a hacer ollas para entender el mundo cerámico de los antiguos y así me tomaron como aprendiz. Lorenza Benavidez, Dora Benavidez y Alejandra Martínez fueron referentes especiales para mi trabajo. Con ellas viví largos períodos en los que hice tareas de recolección de materias primas (antiplástico, arcilla y bosta), preparé las mezclas, amasé, intenté frustradamente levantar piezas, afiné, pulí, colaboré en las quemas así como también en otras actividades domésticas que están inmersas en su vida diaria (por ejemplo, el gerenciamiento de las tareas de cuidado de la casa y la familia). Las entrevistas se realizaron siempre mientras se ejecutaba otra actividad. Si bien la relación más profunda es con ellas tres, realicé numerosas visitas a otras familias en las que realicé entrevistas a las alfareras, por lo general mientras colaboraba con otra actividad, y a otros integrantes de la unidad doméstica.

10 Universos que, tradicionalmente, han sido silenciados a partir de los protocolos de trabajo de la ciencia occidental. 
La vida ritual en Chipihuayco, al igual que en otros sectores de la región surandina11, es muy rica. Los calendarios festivos tienen actividad todos los meses y llama la atención el rol central que tiene la alfarería en ellos. Mi primera pregunta fue para saber si había, dentro de la agenda, algún ritual específico para la alfarería o para las alfareras, pero las respuestas fueron esquivas. Con el correr del tiempo, se comenzó a insinuar que había un ritual que se le hacía al cerro que traía suerte. En efecto, no solo en Chipihuayco sino también en otras comunidades del valle de Talina (en Villa Rosario, Chagua, Berque y Chaquicocha he podido confirmarlo a través de distintas fuentes), se realizan rituales propiciatorios al pie de la veta del antiplástico que extraen; no de la arcilla, sino del antiplástico'12. En nuestro caso, el ritual se realiza en donde se encuentra la veta del antiplástico o pirca Salle, en la quebrada de Esquiloma, a $12 \mathrm{~km}$ a pie desde el centro de la comunidad (fig. 4). Este ritual es central para permitir una fusión entre actores humanos y no humanos, componentes indispensables en este caso para producir artesanas ceramistas.
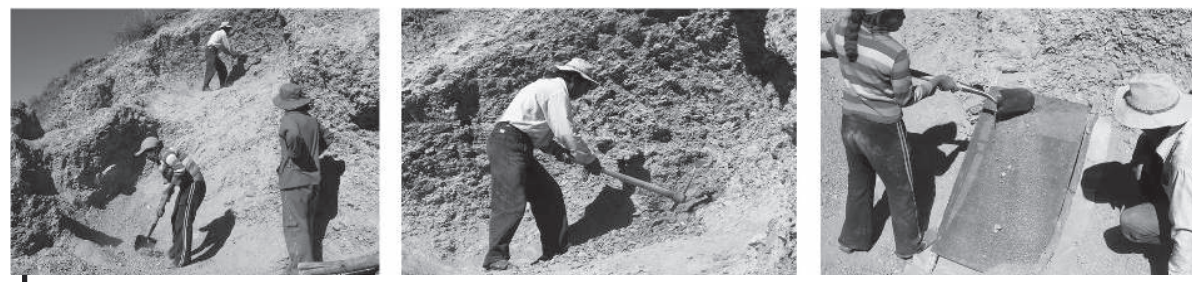

Figura 4 - Procedimiento de extracción de la pirca Salle cercana a Esquiloma

(c) Florencia Ávila

Si bien para la manufactura de las piezas se utilizan tres tipos de antiplásticos y un tipo de arcilla o puca, el ritual solo se realiza a la vera de la veta de la pirca Salle. Para indagar sobre el tema le pregunté no solo a las alfareras activas, sino también a las ancianas, a las jóvenes que aún no se independizan y a los «maridos» de las ceramistas sobre el «por qué» de la Salle. Las razones que me dieron fueron múltiples pero difusas: es la más antigua, es en la que siempre se hizo, es la que hace sonar a las piezas como campanas, es la que hace cocer rojo, entre otras. En palabras de Alejandra Martínez:

Ahora somos todos flojos, haraganes, usamos a veces hasta cuatro pircas.

Antes era distinto. Solo usaban Salle. Seguro que antes todo campaneaba.

El ritual tiene lugar todos los 2 de agosto. Agosto es un mes especial en la región dado que se da inicio al nuevo ciclo agrícola. Es el momento en que la madre tierra, pachamama, se «abre» para recibir las ofrendas rituales que necesita para recuperar su vigor y fortaleza una vez transcurrido el invierno (Fernández Juárez,

${ }^{11}$ Con surandina me refiero a la región que comprende el sur de Bolivia, el norte de Chile y el noroeste de Argentina.

12 En los Andes Centrales hay referencias a rituales pero en relación a la Sañu Mama (madre arcilla), arcilla sin mezclar que tiene la capacidad de transferir el kamay o animu (una suerte de fuerza potente y vital) en la transformación a piezas ya terminadas (La Riva González, 2005). 
1996). En agosto, las familias chipihuayqueñas realizan ofrendas ceremoniales en las chacras de cultivo, en el cruce del río Chipihuayco con el Talina, en el manantial de Santa Cruz, en los dos molinos, en la cisterna de agua y muchos otros, ocupando prácticamente todo el mes. Para cada una de ellas se designa un alférez ${ }^{13}$, pasante ese año, quien se encargará de la abundancia y calidad de las ofrendas, de la elaboración correcta y específica de los platos rituales y del comportamiento de los participantes. En cada uno de estos lugares hay un mojón, una boca abierta de la tierra, que se reconoce por estar cubierto con un montículo de piedras blancas. Es allí en donde se dispondrá de una «mesa ritual» característica de agosto (Martínez, 1987). Estas constan de hojas de coca, grasa de llama, «dulce mesa» que es un conjunto de elementos dulces previamente seleccionados, plantas de coa para sahumar, alcohol, confite y lana de diferentes colores. Todo se dispone en un orden particular y se acompaña de libaciones (ch'alla). Terminado agosto y sus rituales, la tierra, ya satisfecha de su apetito ceremonial, aparece simbólicamente preparada para que comiencen las labores de la siembra (Fernández Juárez, 1996).

Es en este marco de celebraciones cuando se realiza el ritual a la pirca Salle. Al mismo pueden concurrir cualquier miembro de la comunidad, aunque mayoritariamente son alfareras (activas o jóvenes) y la concurrencia varía año a año. Mi presencia allí fue casi de casualidad. Una vez que me enteré que se realizaba este ritual, intenté ser invitada, pero para mi sorpresa (he participado siempre en muchos rituales) se mostraron evasivas. Por lo que, cuando se dio la oportunidad, en el año 2017, traté de pasar lo más desapercibida posible, sin utilizar grabadores ni cámaras. La elección del alférez no tiene nada que ver con su relación con la cerámica, al igual que en todos los rituales, su elección es azarosa y varía anualmente. Es en el Thuro Orkhona14, en el sacadero de pirca, donde se encuentra el mojón, señalado por una acumulación de piedras blancas, que indican dónde está el pozo (o boca de la tierra) que se debe abrir. Es el alférez y su familia los que harán siempre las primeras acciones, invitando luego al resto de los concurrentes. Estas acciones están muy estudiadas, dado que su realización errónea puede traer consecuencias graves para la comunidad. Particularmente me mencionaron dos. La primera, es que la pirca salga contaminada, esto quiere decir que salga mezclada con tierra lo que produce que se rajen las piezas en su cocción. La segunda, es que se desmorone la veta. La pirca se extrae con pico de forma lateral, formando pequeños socavones. Los rumores que se oyen nos dicen que varias personas han fallecido producto del derrumbe del cerro, dejándolas sepultadas. Las razones posibles es que no hayan presentado respeto al cerro, o que los haya ganado la avaricia y sacaron más que lo que necesitaban15.

13 Persona, o familia, elegida anualmente, responsable de la realización del ritual.

${ }^{14}$ Mis interlocutores definieron estas palabras quechuas como Thuro: barro, Orkhona: sacadero. No he podido encontrar aún referencias escritas sobre estos términos.

15 Es interesante que esta situación tenga su eco en los Andes Centrales. Allí, en la región de Conchucos (dpto. de Ancash, Perú), Ramón Joffré (2013) nos plantea una situación muy similar en las canteras de shashal, un antiplástico de piedra pizarra. Los rituales allí circulan en torno a la figura de María Jirai, una heroína quien, luego de construir la iglesia de los pueblos de Huari y Yacya se arroja a 
Una vez abierto el mojón, se comienza a sacar el barro del pozo, allí numerosas personas se acercan para ver cómo sale ese barro (el color y la densidad) y con este salen piezas cerámicas en miniatura que fueron parte de la ofrenda del año anterior (se limpian las piezas que se encuentran sanas y se reponen las dañadas). A partir de lo que sale de la boca, por cómo se presenta el barro y el estado de las vasijas ofrendadas, se evalúa, comentando en voz alta, cómo fue el año en torno a la abundancia, a la prosperidad, a la suerte, a la protección; todos tienen voz, aunque algunos se imponen más que otros. Mientras tanto el alférez ya prepara la mesa ritual para que vuelva a entrar a la tierra. Al lado del mojón, se coloca una manta (aguayo) donde se distribuyen las miniaturas de cerámica que volverán a entrar (el alférez llevó nuevas miniaturas para reemplazar, por si alguna salía rota, en este caso no las hizo una alfarera chipihuayqueña, sino que las compraron en Casira, última comunidad de la quebrada que se dedican a hacer miniaturas). Doce ollitas, doce cantaritos, doce llamas con mankitas (cantaritos) en su lomo. Todo es «cargado», es decir, se llenan los contenedores de confites, romero, dulces, coca, cigarro y se cargan a las llamas con bolsas diminutas de arroz, fideos, azúcar, maíz, trigo, quinoa. Aparte se colocan dos llamas pequeñas que trajo el alférez, una hecha de harina de maíz blanco y otra de harina de maíz kulli (color negro). Se traen también dos figuras humanas (tatalito y mamalita) y un torito, todas hechas con harina de trigo mezclada con tuctuca (grasa de llama que fue comprada en Villazón dado que la comunidad tiene pocas llamas). Una vez todo dispuesto, y bajo la mirada aprobatoria del grupo, el alférez sahúma todas las piezas con coa (planta aromática), las «florea» con lanas de colores y se las ch'alla con alcohol. Ya listo, se coloca todo nuevamente en el pozo, acompañado de comida, coca, cigarrillos y alcohol. Luego el alférez invita a cada asistente para que comparta, con la boca de la tierra, comida, bebida, coca y cigarros (momento en que se crea un compromiso mutuo). Con la boca aún abierta, el alférez comparte con todos comida y bebida, ya relajados, conversando, contando chismes, historias, riendo. Es por la tarde que se procede a cerrar la boca. Las piedras blancas vuelven a amontonarse. Lana de colores, serpentina y papel picado por encima de las piedras darán por finalizado el ritual.

Respecto a la importancia de realizar el ritual, es interesante lo que cuenta Dora Benavidez sobre esto. Cuando se casó con Emilio Vilca, decidió hacer ollas («ser alfarera») y, si bien cumplió con las operaciones a realizar en la casa, la quema no fue buena. Las piezas salían caldeadas (deformadas por el calor) o rajadas. Lo cierto es que solo la práctica ritual en el cerro de Salle permitió su ingreso al universo de los artesanos ceramistas. Dora Benavidez narra su experiencia a partir de un diálogo con su madre: «No he podido, he revoleado barro por todos lados», a lo que la madre (una eximia ceramista) le contestó «¿Cómo va a hacer eso? Tiene que pedir permiso primero. Vamos el 2 de agosto a ch'allar. Vamos a la pirca de Esquiloma». Una vez allí su mamá le dijo que se frotase las manos con la

la laguna de Chutacocha. «Hoy en día cuando alguien llega a estas fuentes de shashal "Tiene que cariñarla [a María Jirai] con cigarro, alcohol, fruta" (A. Ramos)» (Ramón Joffré, 2013: 69). 
tierra que salía del pozo repitiendo «yo quiero aprender a hacer ollas». «Y de esa vez en más he aprendido» señaló Dora.

Como dice Dora Benavidez «hay que ch'allar para hacer olla, hay que hacerse conocer por el cerro». Las recientes alfareras, mediante libaciones y palabras, invocan una relación con los tirakuna (seres-tierra) en la que ambos estarán conectados en una relación de mutua responsabilidad. De hecho, la costumbre de challar en la pirca de Salle se realiza desde hace mucho tiempo, operando como mediador entre los seres de los cerros y las alfareras. Sin duda esta práctica resulta un elemento estructurante de la identidad comunal.

\section{ALFARERÍA, ENSAMBLES Y COMPROMISOS AFECTIVOS}

Al observar la cadena operativa de producción cerámica, notamos que posee una larga trayectoria que va mucho más allá de cuestiones técnicas. Como señala Allen (1998: 20), «debemos aceptar la premisa que todas las cosas materiales (incluyendo cosas que normalmente consideraríamos inanimadas) son agentes potencialmente activos de asuntos humanos». Es en el proceso de elaboración y consumo de la alfarería, donde los gestos, los modos de recorrer los itinerarios de producción, las acciones, cargan la memoria social y contribuyen a la autoafirmación de la comunidad en tanto colectivo.

Tomando en cuenta la propuesta de las arqueologías ontológicas (Petry Cabral, 2014; Alberti, en prensa) sobre la importancia de confrontar nuestros conceptos explicativos frente a los sistemas de conocimiento del otro, así como la propia experiencia etnográfica, decidí que en vez de objetos nucleares (González Ruibal, 2017), un concepto más próximo a la realidad de la comunidad sería pensar en prácticas nucleares. Esta idea refiere a universos de actividades que construyen y ayudan a mantener una identidad comunal. Así la cerámica, en estas comunidades campesinas del sur de Bolivia, trasciende el mero objeto. En efecto, es la red de relaciones afectivas entre sujetos sociales asociada a la alfarería la que deviene en una «práctica nuclear» la cual, dotada de capacidades afectivas, refuerza identidades locales y amalgama al colectivo.

Si retomamos la pregunta que nos plantea Viveiros de Castro «żqué están diciendo los amerindios cuando afirman que los pecaríes son humanos?», en este caso podemos preguntarnos: ¿qué está diciendo la comunidad de Chipihuayco cuando da a entender que lo importante no es la pieza cerámica en sí sino sus redes y ensambles? Desde una perspectiva que entiende a la comunidad como un ensamble, las prácticas nucleares se cargan de un sentido dinámico que puede variar en el tiempo. Recordemos que los ensambles siempre están «en un estado en devenir (...) siempre en proceso, en flujo y fluyendo» (Harris, 2014: 90).

Si bien el proceso es fluctuante, son las redes afectivas las que dan estabilidad. Los actores humanos y no humanos se encuentran aglomerados en redes de afecto. No solo por relaciones de parentesco, compadrazgo, vecindad, oficio, sino también por la memoria afectiva que los vincula, en el espacio y en el tiempo. 
En el caso desarrollado con anterioridad, podemos ver cómo Dora Benavidez, a través de su madre, logra una relación de compromiso afectivo mutuo con la pirca, algo que perdurará por mucho tiempo, pero en renovación continua. Ésta es la arena en donde se construye un compromiso entre los actores para dar sustento a la comunidad desde las redes afectivas y emotivas (Harris \& SØrensen, 2010). La cerámica como práctica nuclear es, entonces, una forma de activación afectiva intencional que aglutina a los distintos agentes sociales.

Es en este contexto ontológico donde es posible entender el status y la importancia central de las alfareras como constructoras y reproductoras de la identidad comunal. Como mediadoras entre mundos y materialidades diversas. Siguiendo la etnografía arqueológica propuesta, la agencia no es de la persona y de la cosa por separado, si no que la agencia surge de la relación entre humano y no humano. Emerge de la conexión (en tanto conector), en la que «los objetos han sido y son elementos constituyentes e indispensables de la reproducción social» (Olsen, 2010: 37).

En síntesis, a partir de lo discutido, considero que «tomar en serio» el universo cerámico de Chipihuayco consiste en buscar explicaciones que respeten los propios términos y concepciones de la comunidad (Alberti, en prensa). En este sentido un enfoque «relacional», que genera un colectivo entre actores humanos y no humanos, contribuye a que afloren las diferencias ontológicas. Es en estos espacios donde podemos impulsar encuentros interepistémicos lejos de la violencia colonial. Por eso mismo precisamos dedicar tiempo a la comunidad con la que trabajamos, para construir una investigación no «sobre», sino «cerca de», compartiendo los saberes de ambos.

\section{PALABRAS FINALES}

La investigación arqueológica, a pesar de que tradicionalmente haya funcionado como un instrumento de reproducción colonial, viene trabajando en el desarrollo de alternativas que le permitan escapar de la espiral de violencia epistémica. Tal vez, un camino interesante a explorar sea partir del presupuesto de que no es posible aproximarnos al otro si no es considerando sus propios términos (su universo ontológico).

Dentro de una arqueología del presente, la etnografía arqueológica nos permite un encuentro cotidiano con el otro y su universo, por lo que, como sostiene González Ruibal (2017: 271), no podemos limitarnos a convertirla solo en una fuente de observación de analogías. Tenemos la oportunidad de involucrarnos con la alteridad, de ser afectados y transformados como personas y como investigadores (Petry Cabral, 2014: 122). Es aquí donde emerge el potencial de una etnografía arqueológica recursiva.

Es a partir de esta perspectiva que nuevos desafíos se manifiestan. Por ejemplo, discutir otras prácticas nucleares en esa comunidad y su relación con el universo cerámico, entender el lugar de las herramientas de la artesana como sujetos no 
humanos dentro de una compleja red de seres, reflexionar sobre la agencia de las alfareras ya fallecidas o comparar los rituales en torno a las canteras de materias primas a lo largo de la Quebrada. Nuevos caminos en los que sean «tomados en serio» los contextos, las cosas, los sentidos y las personas.

\section{Agradecimientos}

Quisiera comenzar por agradecer a los editores Gabriel Ramón Joffré y Catherine Lara quienes fueron los artífices de los encuentros en Ibarra y en Cali. Con gran generosidad crearon espacios de discusión, reflexión e interacción de experiencias e ideas en el campo de la etnografía arqueológica cerámica, del cual este artículo es producto. A mis colegas que participaron de estos eventos porque vi reflejado y también discutida mi propia investigación. Mi agradecimiento a Ben Alberti quien me brindó reflexiones y sugerencias que me llevaron a repensar algunos conceptos operativos, principalmente los relacionados con el campo de la recursividad. A Alfredo González Ruibal que me orientó hacia una definición ontológica. A los revisores, puesto que gracias a sus comentarios se pudo mejorar sustancialmente el escrito. A la comunidad de Chipihuayco y, en particular, a Dora Benavidez, Lorenza Benavidez y Alejandra Martínez, por permitirme entrar en su mundo y compartir la vida diaria. Esta investigación se encuentra financiada por el Consejo Nacional de Investigaciones Científicas y Técnicas (CONICET, Argentina).

\section{Referencias citadas}

ALBERTI, B., 2013 - Archaeology and Ontologies of Scale: The Case of Miniaturization in First-Millennium Northwest Argentina. In: Archaeology After Interpretation: Returning Materials to Archaeological Theory (B. Alberti, A. M. Jones, J. Pollard, eds.), 43-58; California: Left Coast Press.

ALBERTI, B., 2016 - Archaeologies of ontology. Annual review of anthropology, 45: 163-179.

ALBERTI, B., en prensa - Recursive archaeology: an ontological approach.

ALBERTI, B., FOWLES, S., HOLBRAAD, M., MARSHALL, Y. \& WITMORE, C., 2011 "Worlds Otherwise" Archaeology, Anthropology, and Ontological Difference. Current anthropology, 52 (6): 896-912.

ALBERTI, B. \& MARSHALL, Y., 2009 - Animating Archaeology: Local Theories and Conceptually Open-Ended Methodologies. Cambridge Archaeological Journal, 19 (3): 344-356.

ALLEN, C. J., 1998 - When Utensils Revolt: Mind, Matter, and Modes of Being in the PreColumbian Andes. RES: Anthropology and Aesthetics, 33 (1): 18-27.

ALLEN, C., 2017 - Pensamientos de una etnógrafa acerca de la interpretación en la arqueología andina. Comentado por Bill Sillar \& Marisa Lazzari. Mundo de Antes, 11: 13-68.

ÁVILA, F., 2013 - Estabilizar la experiencia material: diferencias y similitudes contextuales de la alfarería yavi-chicha (frontera argentino-boliviana, siglos XI a XVI). Relaciones de la Sociedad Argentina de Antropología, 38 (2): 377-399.

CANUTO, M. A. \& YAEGER, J, 2000 - The Archaeology of Communities: a New World Perspective, 280 pp.; London: Routledge. 
FAVRET SAADA, J., 1990 - "Etre Affecté ". Gradhiva : Revue d'Histoire et d'Archives de I'Antropologie, 8: 3-9

FERNANDEZ JUÁREZ, G., 1996 - El mundo abierto: Agosto y Semana Santa en las celebraciones rituales aymaras. Revista Española de Antropología Americana, 26: 205-229.

GNECCO, C., 2009 - Caminos de la Arqueología: de la violencia epistémica a la relacionalidad. Boletim do Museu Paraense Emílio Goeldi. Ciências Humanas, 4 (1): 15-26.

GONZÁLEZ RUIBAL, A., 2017 - Etnoarqueología, arqueología etnográfica y cultura material. Complutum, 28 (2): 267-283.

GUTIERREZ, W., 2005 - Alfarería de la Nación Chicha. Cosmovisión, Historia, Arte y Tecnología vivas de la cerámica Chichas. Informe técnico realizado por la Secretaría de las Culturas de la Gobernación de Tupiza.

GRECCO PACHECO, D., 2019 - Ontologías envueltas: conceptos y prácticas sobre los envoltorios de tejido entre los mayas. Antipoda. Revista de Antropología y Arqueología, 37: 119-135.

HABER, A., 2013 - Anatomía disciplinaria y arqueología indisciplinada. Arqueología, 19: 53-60.

HAMILAKIS, Y. \& ANAGNOSTOPOULOS, A., 2009 - What is Archaeological Ethnography? Public Archaeology, 8 (2-3): 65-87.

HARRIS, O. J. T, 2014 - (Re)assembling communities. Journal of Archaeological Method and Theory, 21 (1): 76-97.

HARRIS, O. J. T. \& SØRENSEN, T. F., 2010 - Rethinking emotion and material culture. Archaeological Dialogues, 17 (2): 145-163.

HODDER, I., 2012 - Entangled: an archaeology of the relationships between humans and things, xi + 242 pp.; Malden: Wiley Blackwell.

HOLBRAAD, M., 2009 - Ontology, Ethnography, Archaeology: an Afterword on the Ontography of Things. Cambridge archaeological journal, 19 (3): 431-441.

LA RIVA GONZÁLEZ, P., 2005 - Las representaciones del animu en los Andes del sur peruano. Revista andina, 41: 63-88.

MARTÍNEZ, G., 1987 - Una mesa ritual en Sucre: aproximaciones semióticas al ritual andino, 134 pp.; La Paz: HISBOL.

MINH-HA, T., 1989 - Woman, Native, Other: Writing Postcoloniality and Feminism, 184 pp.; Bloomington: Indiana University Press.

OLSEN, B., 2010 - In Defense of Things: Archaeology and the Ontology of Objects, 208 pp.; Plymouth: Altamira Press.

OLSEN, B., SHANKS, M., WEBMOOR, T. \& WITMORE, C., 2012 - Archaeology. The Discipline of Things, 266 pp.; Berkley: University of California Press.

PETRY CABRAL, M., 2014 - "E se todos fossem arqueólogos?": experiências na Terra Indígena Wajãpi. Anuário Antropológico, II: 115-132.

RAMIREZ RIVAS, N., 2014 - Tierra, agua, aire, fuego y arte, 206 pp.; Tupiza: Conceptual.

RAMÓN JOFFRÉ, G., 2013 - Las fuentes del estilo: distribución regional de canteras y técnicas alfareras en Conchucos (Ancash, Perú). Bulletin de I'Institut français d'études andines, 42 (1): 29-90.

SAPIENCIA DE ZAPATA, S., MACEDA RASSIT, V. \& VIAÑA UZIEDA, J., 1997 - Inventario de la cerámica aymara y quechua, 81 pp.; La Paz: Unión de Ceramistas Aymara y Quechua de Bolivia. Centro de Investigaciones de Energía y Población. 
SCHIFFER, M. B., 1972 - Archaeological Context and Systemic Context. American Antiquity, 37 (2): 156-165.

SCHMIDT, P. R., 2010 - The Play of Tropes in Archaeology. Ethnoarchaeology as metonymy. Ethnoarchaeology, 2 (2): 131-152.

SPIVAK, G. C., 2011 - ¿Puede hablar el subalterno?, 142 pp.; Buenos Aires: El Cuenco de plata.

TILLEY, C. Y., 1997 - An ethnography of the Neolithic: Early Prehistoric Societies in Southern Scandinavia, 370 pp.; Nueva York: Cambridge University Press.

VARIEN, M. D. \& POTTER, J. M. (eds), 2008 - The Social Construction of Communities: Agency, Structure, and Identity in the Prehispanic Southwest, 336 pp.; Plymouth: Rowman \& Littlefield Publishing Group.

VERHOEVEN, M., 1999 - An Archaeological Ethnography of a Neolithic Community: Space, Place and Social Relations in the Burnt Village at Tell Sabi Abyad, Syria, 304 pp.; Nederlands Historisch-Archaeologisch Instituut.

VIVEIROS DE CASTRO, E., 2013 - The relative native. HAU: Journal of Ethnographic Theory, 3 (3): 473-502.

WEBMOOR, T. \& WITMORE, C. L., 2008 - Things Are Us! A Commentary on Human/Things Relations under the Banner of a "Social" Archaeology. Norwegian Archaeological Review, 41 (1): 53-70. 